\section{Risks of handling HIV}

SIR - It has been thought that infection by the human immunodeficiency virus (HIV) occurs only with exposure to intact virions or infected cells. We assessed the validity of this assumption by attempting to infect the monkey Macaca fascicularis with simian immunodeficiency virus of macaques $\left(\mathrm{SIV}_{\text {MAC }}\right)$ proviral DNA.

Recombinant bacteriophage lambda DNA containing SIV $_{\text {MAC }}$ proviral DNA was prepared as described in refs 1 and 2 . The starting phage stock was expanded in Escherichia coli; the resulting higher-titre suspensions were used to infect aliquots of bacterial host at an m.o.i. of 0.05 . Each infection was cultured in LB medium, bacterial debris removed by low-speed centrifugation and phage sedimented by treating the supernatant with $10 \%$ polyethylene glycol and $1 \mathrm{M} \mathrm{NaCl}$. Particles were precipitated, further purified, and digested with RNase A/Proteinase $\mathrm{K}$ as described in refs 2 and 3. DNA was resuspended in distilled water and adjusted to $0.5-1 \mathrm{mg} \mathrm{ml}^{-1}$. The yield was about $1 \mathrm{mg} \mathrm{l}^{-1}$ of culture. (Further details of the method available on request from N.L.L.)

Four healthy adult $M$. fascicularis each received a single intramuscular inoculation of $200 \mu \mathrm{g}$ DNA. Heparinized blood was taken from these animals once a month following inoculation. Two of these animals had seroconverted by 1 month following DNA inoculation, as determined by indirect immunofluorescence on SIV $_{\text {MAC-infected } \mathrm{H} 9}$ cells. A third monkey seroconverted within 2 months of inoculation. Peripheral blood lymphocytes obtained from the four monkeys at each bleeding were $\mathrm{CD} 8^{+}$lymphocytedepleted, concanavalin A-activated, and expanded in interleukin-2-containing medium. Supernatants of the cultured lymphocytes from the three animals that seroconverted contained reverse transcriptase activity and had gag antigen (p28) detected in an antigen capture assay. We used electron microscopy to demonstrate intact viral particles in the cells of one of these cultures. These culture supernatants also transmitted SIV $_{\text {MAC }}$ infection in vitro to lymphocytes of normal $M$. fascicularis. Thus, intact SIV $_{\text {MAC }}$ could be isolated from peripheral blood lymphocytes of three of the four monkeys inoculated with phage DNA.

The phage DNA did not infect $M$. fascicularis lymphocytes in vitro. Aliquots of $10^{6}$ concanavalin A-activated, interleukin-2-expanded, $\mathrm{CD}^{+}$cell-depleted $M$. fascicularis lymphocytes, despite supporting the replication of intact SIV $_{\text {MAC }}$ virus, did not yield replicating virus after seeding with phage DNA, implying that there was no contamination of the phage DNA preparation with intact virus. re-evaluation. USA
Our observations will facilitate work being done on genetic determinants of AIDS virus pathogenesis in nonhuman primates. Perhaps more important, these findings raise the possibility that AIDS virus DNA by itself may be infectious for laboratory investigators, suggesting that viral DNA handling practices may require

NORMAN L. LETVIN

CAROL I. LORD

NORVAL W. KING

MichaEL S. WYAND

Harvard Medical School,

New England Regional Primate

Research Center,

Southborough, Massachusetts 01772 ,

KYL V. MYRICK

William A. HASELTINE

Dana-Farber Cancer Institute,

Boston, Massachusetts 02115, USA

1. Yamamoto, K.R. et al. Virology 40, 634-744 (1970). 2. Vande Wounde, G.F. et al. Proc. natn. Acad. Sci. U.S.A. 76. 4464-4468 (1979)

3. Sambrook, J., Fritsch, E.F. \& Maniatis, T. Molecular Cloning: A Laboratory Manual (Cold Spring Harbor Laboratory. New York, 1989)

\section{Carbon dioxide and temperature}

SIR-Kuo et al. have shown' that the monthly concentration of atmospheric carbon dioxide at Mauna Loa, Hawaii exhibits statistically significant coherences over a range of frequencies with monthly surface air temperatures averaged over the entire globe. The $\mathrm{CO}_{2}$ record lags behind the temperature record; this lag is consistent with the hypothesis that temperature fluctuations or associated meteorological changes ${ }^{2}$ cause the short-

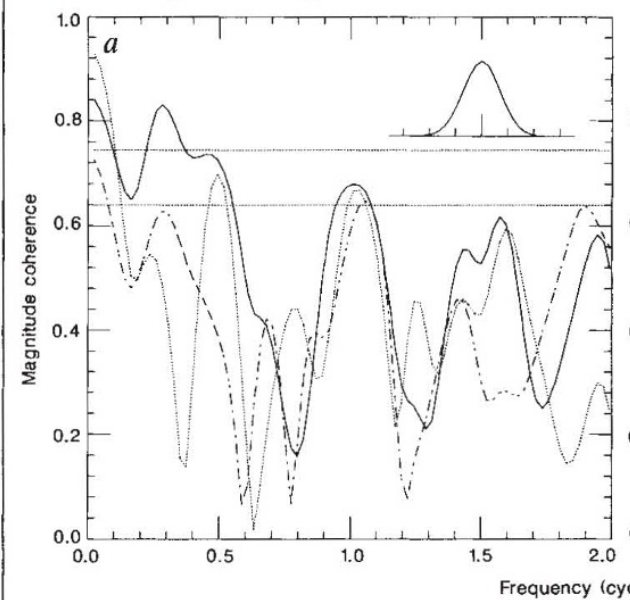

term $\mathrm{CO}_{2}$ anomalies rather than vice versa. In any event, fluctuations in $\mathrm{CO}_{2}$ concentration at frequencies $\gtrsim 0.2$ per year are too small to cause the observed temperature variations by the greenhouse effect. We have analysed air and sea surface temperatures averaged over different regions of the Earth, and find that air temperatures averaged over equatorial regions and sea temperatures averaged over the equatorial Pacific are more highly correlated with the $\mathrm{CO}_{2}$ anomalies than air temperatures averaged over nonequatorial northern $\left(90^{\circ}\right.$ to $\left.23.6^{\circ} \mathrm{N}\right)$ or southern $\left(90^{\circ}\right.$ to $\left.23.6^{\circ} \mathrm{S}\right)$ regions. This result suggests that the sources and sinks of atmospheric $\mathrm{CO}_{2}$ in question lie in the cquatorial regions.

We have used the Goddard Institute for Space Studies (GISS) monthly air temperature record from land stations ${ }^{3}$, monthly sea surface temperature (SST) data from the Comprehensive OceanAtmospheric Data Set (COADS) ${ }^{4}$ and the monthly atmospheric $\mathrm{CO}_{2}$ record at Mauna $\mathrm{Loa}^{2}$ to search for coherences between the temperature and the month to month change in the $\mathrm{CO}_{2}$ concentration. The seasonal cycle in both the $\mathrm{CO}_{2}$ and temperature time series is removed by calculating the departures from the mean values for each month of the year. Spectral analysis ${ }^{5}$ allows us to ascertain directly the degree of coherency between the monthly temperatures and the monthly rate of change in $\mathrm{CO}_{2}$ at different frequencies. We use a gaussian spectral window of half-width $\sigma=0.07$ per year and apply a smooth cutoff to each end of the time series to reduce lcakage.

Part $a$ of the figure shows the coherency between the monthly rate of change of $\mathrm{CO}_{2}$ and surface air temperatures averaged over the entire globe, over nonequatorial northern regions and over non-equatorial southern regions during March 1958 to December 1987. The prob-

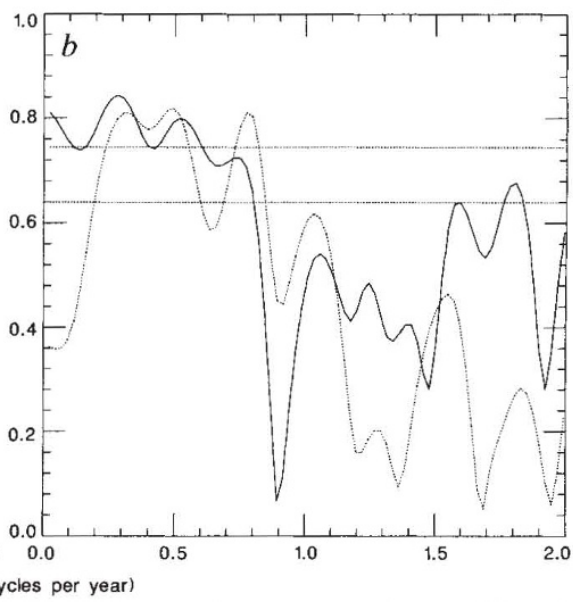

Coherence between the monthly rate of change of $\mathrm{CO}_{2}$ and temperatures averaged over different regions. Upper and lower horizontal lines, $99 \%$ and $95 \%$ confidence limits, respectively. The spectral window appears in the inset of $a$. $a$, Solid line, global air temperatures; dashed line, air temperatures in the northern region $\left(90^{\circ}\right.$ to $\left.23.6^{\circ} \mathrm{N}\right)$; dotted line, air temperatures in the southern region ( 90 to $23.6^{\circ} \mathrm{S}$ ). b. Solid line, equatorial air temperature; dotted line, SST in the equatorial Pacific. 